\title{
Cartaphilus
}

Revista de investigación y crítica estética

PAISAJES INTERIORES EN GALERÍA DE RARA ANTIGÜEDAD

DE JAIME SILES. LA OBRA “DESDE DENTRO”

INNER LANDSCAPES IN GALERÍA DE RARA ANTIGÜEDAD

BY JAIME SILES. THE WORK "FROM WITHIN"

\section{FRANÇOISE MORCILLO}

UNIVERSITÉ D'ORLÉANS (FRANCIA)

\begin{abstract}
Resumen: Este escrito ejecuta una revisión de los aspectos poéticos de la obra del escritor valenciano Jaime Siles a partir de su poemario Galería de rara antigüedad, que fue merecedor del XXVIII Premio de poesía Jaime Gil de Biedma en 2018. En el curso del texto, asimismo, se comentará la cuestión relativa a la la práctica del monólogo interior con su concepción autorial de la poesía íntima, en particular, así como de sus imbricaciones en la literatura griega antigua o la tradición europea moderna, en general, de la que Jaime Gil de Biedma fue un epígono esencial en el panorama de la creación literaria española en el siglo XX.
\end{abstract}

Palabras clave: Jaime Siles, Poesía, Museo, monólogo poético

\begin{abstract}
This writing carries out a review of the poetic aspects of the work of the Valencian writer Jaime Siles from his collection of poems Galería de rara antigüedad, which deserved the XXVIII Jaime Gil de Biedma Poetry Prize in 2018. Over the course of this work the discussed issue will also consider the the inner monologues practice in its relation to Sile's authorial conception of intimate poetry, in particular, and its entanglements in Ancient Greek literature or European modernism tradition, in general, of which Jaime Gil de Biedma was an essential epigone in the Spanish literary scene in the 20th Century.
\end{abstract}

Keywords: Jaime Siles, Poetry, Museum, Poetic monologue 
Autor de Génesis de la luz (1969), Biografía sola (1971), Canon (1973, Premio Ocnos), Alegoría (1977), Poesía 1969-1980 (1982), Música de agua (1983, premio de la Crítica), Colvmnae (1987), Poemas al revés (1987), El gliptodonte y otras canciones para niños malos (1990), Semáforos, semáforos (1990, premio Loewe), Poesía 1969-1990 (1992), Himnos tardíos (1999, Premio Generación del 27), Pasos en la nieve (2004), Colección de tapices (2008), Actos de habla (2009, Premio Ciudad de Torrevieja), Desnudos y acuarelas (2009, Premio Tiflos), Horas extra (2011), Cenotafio: antología poética, 1969-2009 (2011), Tardes de Salamanca (2014), el poeta Jaime Siles recibe con Galería de rara antigüedad (2018) el XXVIII Premio de Poesía Jaime Gil de Biedma.

Cabe notar que desde la publicación de su libro Actos de habla (2009), el poeta invita a navegar por el piélago de la íntima identidad de serse un hombre de humanidades. De hecho, tanto sus libros de poemas como sus labores de ensayista, de crítico literario, de traductor y de estudioso de la epigrafía recortan el espacio de una defensa, la de las humanidades, cuando éstas suelen ser tan despreciadas hoy en día. En ese sentido, lo apremia la entrevista del ABC Cultural en cuyo titular autoproclama dicha defensa: "Las humanidades nos enseñan a no confundir precio y valor" (Siles, 2014). E incluso recordemos las palabras del poeta en la Fundación Juan March en enero del 2019, cuando declara que la filología ha iluminado su vivir reconociéndose obviamente como un doctus poeta. Retomaré aquí las sendas de esas iluminaciones que no tienen nada que ver -a mi juicio- con las Iluminaciones de Rimbaud ni del famoso yo es otro para solidarizarse más bien con el yo que se distancia de sí mismo, ficcionalizándose en ese yo que ya no es él. De un yo que se anula en el tiempo y que se sucedió estéticamente como un canon musical con repique de voces parmenidianas, que recortan la identidad de serse en una sucesión de sombras interiores en forma de alegorías pensamientos en imágenes- que se detuvieron en el poema como una "negación gozosa", "apotegma del yo como accidente". Son pausas creadoras éstas de tiempos detenidos que cuestionan "Interiores":

¿O lo que aquí llamamos música pudiera

muy bien llamarse el ala de una duda

y el paraíso firme que sostienen

interiores columnas de temblor?

(Siles, 1992: 102)

Parece ser que el autor de Galerías de rara antigüedad se apresure en introducir a la lectura de ese "paraíso firme" que se ha de entender como perenne 
entrega creadora a la escucha de la antigüedad leída y vivida desde un adentro o paisaje interior "como filología implícita"

\section{UN PAISAJE INTERIOR COMO “FILOLOGÍA IMPLÍCITA"}

De las generaciones de los textos que hay en la tierra sólo habré leído unos pocos, los que sigo leyendo en la memoria, leyendo y transformando. (Jorge Luis Borges, Elogio de la sombra)

El texto es el único escenario para representar ante mí mismo imágenes cambiantes de mi vida y fragmentos perdidos de mi idea de lo que creo fue la Antigüedad.

(Jaime Siles, Galería de rara antigüedad, 2018)

A semejanza de Jorge Luis Borges en su Elogio de la sombra o a la de Paul Veyne en Mon musée imaginaire (2012), fascinado éste por la pintura italiana, Jaime Siles dibuja, a su vez, su línea de sombra en la greciedad. Y aquí conviene dar incluso a la sombra una acepción japonesa, aquella que trazó la creación de Tanizaki Junichiro (1886-1965) con su propio Elogio de la sombra, explorando sus mundos secretos en los que los actos más sencillos resultan ser entregas artísticas que nos hablan de lo desaparecido.

Como Borges en "Las cosas" -que "durarán más allá de nuestro olvido; / no sabrán nunca que nos hemos ido" $(1994,370)-$, Siles afirmará que es "la fuga de sentido lo que nos reescribe" (2019: 63). De hecho la Antigüedad es su mundo como filólogo y como poeta. Este ámbito entretejido por ambos conocimientos abarcan el fluir y los pasos de su vida. Se da esta "intimización" desde una rareza creadora, la misma que conoció y expresó Catulo haciendo de su persona el sujeto de su obra. Jaime Siles ficcionaliza los goces de lector, sus andanzas quijotescas por las lecturas no de los libros de caballerías sino desplazando la ambivalencia barroca del engaño desengaño hacia la epopeya griega bimembre de la lliada y la Odisea convertida en prosopopeya: figuras ausentes y dialogantes.

En esta materia, no se llama a retroceder al mundo del pasado, sino que desea invitarnos a valorar en él el legado cultural para leer el claroscuro de nuestra propia identidad bajo la entrega del lenguaje. Sin esa toma de defensa, la sociedad se desarraiga y pierde su vitalidad crítica. Resulta necesario entonces inyectar una nueva savia creadora en forma de desafío en cada libro publicado. $Y$

\footnotetext{
${ }^{1}$ Para Jaime Siles, "la Filología implícita es la que los escritores y poetas ponen en la escritura de su propia obra en práctica: es, pues, una Filología endógena" $(2019,31)$.
} 
eso es lo que acierta a hacer Jaime Siles en cada uno de sus libros: logra inscribirse en el tiempo dentro de la tradición intercultural.

Detengámonos en cuestionar "ese adentro", aclarándolo con la linterna crítica de El defensor ${ }^{2}$ de Pedro Salinas. Por supuesto, un ensayo que nos da a entender que el defensor lo es en realidad de la lectura. $Y$ conviene notar que en el capítulo que lleva por título "El defensor de la lectura" $(2002,117)$, Salinas enuncia el trabazón de un doble arte, el del ars moriendi y el del ars legendi, con repique de voz sonetista de lectura quevediana: "Vivo en conversación con los difuntos, / y escucho con mis ojos a los muertos" (117) ${ }^{3}$. A su vez, este doble transitar por la lectura y el comercio de las almas debe referirse al diálogo literario, según Salinas:

¿De dónde procede el favor del diálogo como forma literaria en la antigüedad? ¿No es el diálogo una forma emanada de un grupo de interlocutores, de una minoría de hombres que se deleitan en alumbrar ideas? Cierto que los diálogos son muy pronto una forma ficticia... (227)

En ese sentido, la presente obra de Jaime Siles dialoga con las sombras de las figuras de la Antigüedad que fueron en sus días lecturas gozadas. Y éstas se ficcionalizan en una intimización de protagonismos de ser o no ser en "Mnamón el cretense", "Phoinikastas", "Meránides el frigio", "Belerofonte lamenta su suerte", "En la tumba de Lícidas", "Antístenes el cínico", "Epiménides de Creta”, "Cínidas el locrio" y "Aristón el gramático". Por ventura, la espacialidad de la Antigüedad se convierte en especial rareza, la de hablar de sí mismo desde las vidas de ciertas figuras griegas.

Ahora bien, el lector del siglo XXI puede representarse la Galería de la Antigüedad como una galería de arte. Una visión creacionista e intimista propia y apropiada por la memoria del poeta que va reverberando "líneas de sombras", en cuyos interiores podría revelarse el trasfondo de otra galería, la del comercio de las almas que conversan con los difuntos. Es de notar que el viaje ficticio por galerías de rara antigüedad conlleva a ahondar un tiempo de duelo de sí mismo, y que se da en el dramático ir viviendo el desaparecer.

Si en principio el lector no se halla ante un libro de filología, sí que se encuentra ante un transtexto anímico de la Antigüedad creadora en cuyo origen no ha de anegarse el lector, sino que éste ha de atravesar un pasaje doloroso para

\footnotetext{
${ }^{2}$ Cabe precisar que Jaime Siles dedica a Pedro Salinas uno de los ensayos de Estados de conciencia: ensayos sobre poesía Española contemporánea. En "Pedro Salinas: la escritura total", Siles retoma los pasos reflexivos del poeta sobre el acto de leer, para quien leer era "sentir con los personajes", la lectura "una forma de compasión", y "un clásico tiene que estar siempre dispuesto a rendir cuentas de su valor "(88).
}

\footnotetext{
${ }^{3}$ Salinas cita los versos del soneto quevediano, "En conversación con los difuntos".
} 
demorarse en la extensión de un "paisaje interior" como expresión identidaria de una filología implícita que celebra el poeta. Me complace leer esta obra de poemas o entrada en la galería de rara antigüedad con la antorcha ensayística de su libro Injertos y trasplantes. La traducción como proceso creativo, publicado en 2019. En él, el poeta se centra en "la traducción como creación" (45) y no como mero traslado textual. $Y$ el agente generador de esta creación se desvela en el acto creador "de fingirse otro". Un acto que da a entender la transmisión de la tradición literaria, ya que el poeta subraya que La llíada, por ejemplo, "ofrece pasajes (...) que son o han sido traducción de textos ugaríticos" (46).

A la hora de leer los diecisiete extensos poemas que componen Galería de rara antigüedad (2018), al lector le toca poner a prueba la referencia del poeta al teatro latino para sugerirnos que si éste en principio escoge la readaptación de obras griegas, lo hace desde una contextualización latina:

en el que se hace la ficción de que la escena es griega, los personajes sean griegos, la indumentaria sea griega..., pero los actantes hablen y se expresen en latín. (47)

A continuación, notemos en esta galería de rara antigüedad cómo el poeta se apropia, pues, de la greciedad para convertirla en gracia creadora que despierta en mí otra galería de pintura textual. Aquella misma escenografía textual que practicaba y predicaba en sus jóvenes oyentes el biógrafo Philostrate de Atenas (2013). Conviene apreciar que en dicha práctica de lectura creadora, el filósofo se libraba a interpretar lo invisible de las pinturas de la Antigüedad, despertando en el oyente la fascinación por otra pintura invisible nacida de la emoción que transmite el acto creador. Se procede, aquí, a una educación de la imaginación, enseñando a presenciar la lectura de lo invisible.

Precisamente la cuestión de lo invisible es un debate en toda la obra de Jaime Siles, y me atrevo a decir que va en aumento. Parece ser que desvele su presenciarse en el transplante de la greciedad hacia la lengua castellana haciendo que la oralidad en la escritura del poema se halle cuajada de "arrepentimientos" (2019: 31) $)^{4}$ biográficos.

\section{LA RAREZA DE LOS PAISAJES INTERIORES: LOS ARREPENTIMIENTOS BIOGRÁFICOS}

Paisajes interiores son presentidos, porque recortan estos moradas literarias que se han dado anteriormente como Himnos tardíos (1999) en su "De vita philologica" o "sombras de diccionarios", y que ahora sólo fingen "arrepentimientos biográficos" que se entregan en forma de proceso creativo. Emana la plasticidad de la propia escucha anímica del transplante orgánico, de su grecie-

\footnotetext{
${ }^{4}$ El poeta relaciona la filología implícita con el proceso del arrepentimiento pictórico.
} 
dad literaria en la que el poeta se ha iniciado al monólogo dramático desde las obras de Catulo antes de que tal proceso creador se cultivara en las del poeta romántico inglés Browning y en las de sus sucesores célebres: Fernando Pessoa, José Luis Borges, Luis Cernuda, José Ángel Valente, Jaime Gil de Biedma. Y, a día de hoy, en las incursiones en la materia del monólogo dramático de Guillermo Carnero, de Luis Antonio de Villena, para evocar en ambos cierto humanismo desapercibido, con matices en el primero de figuras de la historia artística europea olvidada y en el segundo de un alejandrinismo auto-retratador.

¿Cómo interpretar la práctica del monólogo dramático en esta galería silesiana? Quizá se de como memorias en forma de diario de "filología implícita" modulable en "arrepentimiento" de la voz poemática.

Recordemos que el arrepentimiento en pintura se refiere a las posibles modificaciones que puede tomar un artista en su lienzo. Numerosos son los ejemplos en las obras de Murillo, de Velázquez, Picasso o Degas que encubren, en sus lienzos pintados al óleo, ciertas figuras que no aparecen visibles a primera vista. A estas figuras las rescata la técnica del infrarrojo aplicable a la resolución o sazón de la "irrealidad de la memoria" o de la lectura de esas líneas de sombra reparadas en la obra de Jaime Siles.

Cuando Jaime Siles abre su galería de rara antigüedad con el poema "La cuestión homérica: a vueltas con la llíada", percibimos cómo se reverbera la epopeya en un doble trasvase frástico y de castellano hablado:

Delante de mis ojos veo a Aquiles combatiendo.

Mirmídones y dólopes no se quedan atrás:

Avanzan con todo su pesado armamento, mientras

Héctor y los troyanos cierran filas en frente

y las flechas de ambos se cruzan en el aire

como enjambre de abejas

y las lanzas de bronce brillan bajo el intenso sol.

(Siles, 1999: 11)

Notemos que este escenario emana de un proceso de juvenil y precoz lectura de los versos de La llíada. Parece ser que este primer cuadro de epopeya se resuelve en escritura oralizada aquello que sólo fue una emoción de joven lector de La llíada. Posiblemente no nos hallamos ante un mero recuerdo de lectura, sino ante un retorno o "a vueltas con" La llíada. Y en la sinuosidad versátil del cante homérico -"cada ser humano es un relato, cada héroe /es una canción" (1999: 11). Conforme se despliega el poema, asistimos a otra vuelta de tuerca con, esta vez, "El defensor de la lectura" que fue Salinas, cuando precisa el paso del arte moriendi al arte legendi: "Al final de la Edad Media, las congojas que 
sentían los humanos ante la idea de la muerte originó gran número de Artes de morir. En un Ars moriendi se hallaban los avisos para morirse como es debido, esto es -o esto era-, con las cuentas del alma bien ajustadas (...). En nuestros días se multiplican los Artes de leer" (2002: 136). En el poema "A vueltas con la Ilíada" se revierte el arte, ya que partimos del ars legendi para conversar con el ars moriendi. No se trata de confundir la epopeya de los héroes homéricos con nuestra epopeya de seres mortales, sino de tener en cuenta que la cuestión homérica pone en evidencia nuestra fragilidad humana de mortales. Y es cuando surge la urgencia creadora de ficcionalizar nuestras vidas, nuestros seres queridos para que estos incorporen el panteón babélico de la Literatura. Gracián nos declama su "vivir es milicia en la tierra", mientras Jaime Siles se apropia de la espacialidad de la Odisea, del Canto XI, con voz de monólogo dramático homérico, para sugerirnos esos retazos de arrepentimientos biográficos homerizados:

La poesía nos separa de los nuestros

y yo, y mis viajes, hemos sido materia de canción. (15)

O

Madre- le dije- ¿veré, crecido ya

a mi hijo, y me reuniré al fin con mi mujer? (15)

En realidad, el arrepentimiento biográfico valorado en proceso de creación difuminado en el lienzo de "la vida-poema" salva la exclusividad de la intimidad, incorporando ésta en forma de vida literaria. En "Odisea, nueva versión del canto XI" escuchamos la voz híbrida de dos almas intercambiadas para el oyente e inconfundibles para el poeta: Madre o Anticlea susurran la filiación alentadora de la esperanzada eternidad del volver a ser "cantable":

las que más prefiero recordar: "hijo mío, la Noche

dura un muy breve instante tras del cual hay

no la tenue luz de oro viejo tibio que ayer viste

sino otra, hecha de la más sonora claridad". (15)

No obstante, el arrepentimiento biográfico se vale de la figura de Mnamon el cretense (Siles, 19), el memorioso, obsesionado por hacer inventario de todo cuanto le rodeaba, aunque el gran fallo de su vida radicó en no apreciar lo debido el buen uso de la memoria, ya que ésta ha de actuar para conocerse a sí mismo. El poeta escoge la vía de Phoinikastas, que desea, a diferencia de Mnamón, no depender de su memoria y olvidarse para transmitirse sólo en forma de escritura: 
¡Ojalá yo no tenga que depender de mi memoria!

(...)

y me dejen tranquilo dibujando los signos

sobre esta tablilla de barro para siempre,

pues eso es lo que quiero: eso y nada más!

(21-22)

El arrepentimiento biográfico traduce la distanciación a la figura de Epiménides de Creta y la renuncia a la creación epifánica. A diferencia de éste, que se nos dice que recibió revelaciones de la Justicia y la Verdad, la voz poética acorta el relato para negar el encuentro con ambas. En nuestro mundo inmundo ni se dan ni la justicia ni la verdad:

Llevo sesenta y cinco años

de un lugar a otro

por el mundo,

sin que en ningún sitio

ninguna de ellas se haya dejado ver. (33)

De lleno en la lectura de galería de rara antigüedad, el poeta conversa con ese adentro de su propia creación poética, devolviendo la realidad a lo clásico:

porque el texto nunca muere ni acaba:

está empezando siempre cada vez.

No es el carácter inagotable de lo clásico:

es el carácter y condición del Ser.

nosotros sólo somos su pausa. (44)

Este libro es una pausa de la reverberación de las lecturas griegas entretejidas de arrepentimientos biográficos en plena posesión de una maestría, la del arte del monólogo dramático.

\section{MONÓLOGO DRAMÁTICO Y PREMIO XXVIII JAIME GIL DE BIEDMA}

Acierto real del jurado que concedió a Siles el premio Jaime Gil de Biedma, puesto que este poeta fue un defensor del monólogo dramático al que dedicó su razón poética: "lo que yo creo es que siempre que un poeta habla en un 
poema, quizás no hable como personaje imaginario, pero como personaje imaginado, siempre" (Gil de Biedma, 2002: 67).

Establezco un puente de fraternidad literaria entre ambos, porque tanto en la obra de Jaime Siles como en la de Gil de Biedma lo que se valoran son las personas: "mi interés primordial son las personas" (80).

De cierto modo, en Galería de rara antigüedad no asistimos a las proezas del batallar de los héroes, sino a desentrañar sus atributos físicos y morales, que aparecen como tantos signos distintivos o caracteres y pasan a ser arrepentimientos humanos o ficciones disueltas.

Pero en Galería de rara antigüedad, más allá del rescate de una juvenil lectura, se intima la pausa del haber sido lector y seguir siéndolo, existiendo dentro de la ficción o desde el enfoque de la irrealidad de la memoria. Estas pausas no son en nada retazos de recuerdos, sino vivencias dentro de la lectura de textos griegos que nutren la identidad de sentirse ser a través de lo extranjero o de lo distante de una ipsidad reversible -"Ipsa, sed altera; Altera, sed ipsa" (Poemas al revés: 1986)-, con lo cual la llíada se amansa en un celaje hexamétrico que abarca retribuciones, es decir, a su vez estímulo y gratificación que el lector y el estudioso de filología latina ha ido recibiendo constantemente de ese ars legendi de los clásicos. La cuestión homérica es también casi una vuelta a recordar los epigramas y el soplo creador y humanista de Marcial que reactualiza José Guillén en 2003:

¿Qué placer te provocan los vacuos divertimentos de un pobre papel? Lee aquello de lo que la vida pueda decir: ' $i E s$ mío!'. Aquí no encontrarás ni centauros, ni gorgonas, ni harpías: mis páginas saben a hombre. (Marcial, 2003: 17) ${ }^{5}$

La declaración de "Mis páginas saben a hombre" impacta la obra de Jaime Siles, dado que éste no retoma la cuestión homérica en plan académico, sino en plan de poeta. Y en cierto modo, el poeta Siles alcanza el arte de hablar la Antigüedad, compartiendo con Yves Bonnefoy el territorio interior en el que sorprendemos "Una mirada, un temblor interior: una memoria dentro de mí, más profunda que la conciencia, o más presta al acecho, lo había comprendido antes que yo"(Bonnefoy, 12).

\footnotetext{
${ }^{5}$ Cf. En una esclarecedora nota a pie de página, José Guillén reactualiza el presenciar el elemento humano en la obra: "10, 4, 7-10. El libro que quiera ser inmortal "debe tener genio", 6, 61, 10. Cf. E. B. Viejo Otero, El elemento humano en la obra de Marcial: Escorial 50 (1944), 387-396. Uno de los puntos de la polémica literaria de Marcial se basa precisamente en que él considera la epopeya y la tragedia por los elementos mitológicos de que se sirven en ellas; Marcial les opone la realidad de la vida cotidiana, cf. M. Citroni, Motivi di polemica letteraria negli epigrammi di Marziale, DArch2 (1968), 259-301" (Marcial, 2003: 17, nota a pie 114).
} 
¿Qué persigue lograr el poeta? Tal vez sacar a la luz un idioma que hable ese raro idioma de un yo sin mí.

Aquí conviene recordar que Jaime Gil de Biedma invocó a las personas del verbo para sugerirnos el acto poético como una firma pronominal simbólica, tomando por punto de partida del yo, el roce del tú interlocutor, en espera de coincidir o acercarse al "con ellos" a los recuerdos vividos brindándonos de pasada las contradicciones sociales entre el "nosotros" y el "vosotros". Aunque con él, ya no se trataba sólo de retroceder a los recuerdos, sino de conversar con esas elegías múltiples de su voz poética dentro de la literatura y su historia. Y tomar por compañeros de viaje, o por experiencia de vida, el dialogar con los difuntos. Retomaré de este experto en el monólogo dramático esta declaración: "Yo creía que quería ser poeta, pero en el fondo quería ser poema" (Gil de Biedma, 2002: 259).

En realidad, ese "quería ser" lo podemos relacionar con La realidad y el deseo de Luis Cernuda. Porque, como bien señala Jaime Siles en su ensayo Estados de conciencia, "para Jaime Gil de Biedma, "La realidad y el deseo es una íntima reflexión sobre la existencia moral e intelectual de Luis Cernuda y, en segunda instancia una meditación sobre la vida": lo que, con palabras de Arnold, llama criticism of life (Siles, 2006: 164). Acaso Gil de Biedma atravesó los límites de la poesía social desde las invocaciones de sus resentidas contradicciones personales, pero su obsesiva inquietud del tiempo y del yo le anegaron como a Narciso en el inicio de su madurez robada a la vida.

Extraña resulta ser esta otra declaración suya en el prólogo a Compañeros de viaje (1959):

Muy pobre hombre ha de ser uno si no deja en su obra - casi sin darse cuentaalgo de la unidad e interior necesidad de su propio vivir. Al fin y al cabo, un libro de poemas no viene a ser otra cosa que la historia de un hombre que es su autor, pero elevada a un nivel de significación en que la vida de uno es ya la vida de todos los hombres o, por lo menos - atendidas ya las inevitables limitaciones de cada experiencia individual- de unos cuantos entre ellos (7).

Con esta cita se establece una sintonía entre Jaime Gil de Biedma y Jaime Siles, aunque este último da un paso más a la escucha de esa voz interior que actúa. Su anterioridad a la conciencia, topando con su raíz más íntima, ese infrarrojo de arrepentimiento y no de resentimiento que le hace ser el que vuelve a ver -como diría Santiago Sylvester - y el que coincide con lo desconocido de las cosas vividas y leídas. Cada libro de Jaime Siles celebra una renovada lectura del tiempo. Sus Himnos tardíos ya potenciaron el tardío reconocimiento de "De vita philologica". No dejamos de recordar el anhelo del poeta cuando en sus primeras entrevistas de la década de los 70 declaraba su deseo de "Ser en la eternidad dentro del tiempo". 
A una nueva vivencia temporal nos somete la lectura de Galería de rara antigüedad, a la de la unidad de ser un poeta que por su sabiduría de filólogo alcanza renovar el arte de hablar la literatura y de cantarla. De modo que consagrar un libro de poemas a la Antigüedad en tiempos de redes múltiples no significa en nada refugiarse en el pasado, sino seguir la galería de la apropiación del pasado para entender que lo raro es vivir.

¿En qué estriba esa rareza? Rara resulta ya esa galería de belleza literaria que le sigue proporcionando la Antigüedad. Rara, porque aunque lejana involucra una doble poética que los poetas modernos han retomado. La del epigrama y la del monólogo dramático. Si la primera forma ha inspirado los sonetos de Jaime Siles, la segunda, la del monólogo dramático, pone en una extensión de versos los encabalgamientos de un poeta lector hablando con su creación. Y Jaime Gil de Biedma, no como clásico sino como moderno, desde la influencia inglesa, subrayaba la toma de conciencia en los poetas ingleses respecto a "la distancia que había entre él, como persona real, y él como personaje poético" (Gil de Biedma, 2002: 68)

En esta galería de rara antigüedad y desde el monólogo dramático griego, Jaime Siles se juega por líneas de sombras el celaje de la venidera Arquitectura oblicua (Siles, 2019), de "la irrealidad de la memoria" que no es sino "uno de los modos de existir" (84). Se divisa el jardín del trasplante elegiaco, en el que un nuevo arrepentimiento biográfico va a surgir bajo la hechura de la elegía germánica, por ser tensión filosófica o existencial de un "aprender a morir como las cosas/ en ellas mismas siempre transformadas" (99).

\section{BIBLIOGRAFÍA:}

BORGES, Jorge Luis (1994): Obras Completas. Tomo II. Buenos Aires: Emecé.

GIL DE BIEDMA, JAIME (1959): Compañeros de viaje (1952 - 1958). Barcelona: Joaquin Horta Editor.

(2002): Conversaciones. Madrid: Austral.

MARCIAL, Marco Valerio (2003): Epigramas. Texto, introducción y notas de José Guillén. Zaragoza: Instituto Fernando el Católico.

PHILOSTRATE (2013): La galerie de tableaux. Préface de Pierre Hadot. Paris: Les Belles Lettres.

SALINAS, Pedro (2002): El defensor. Madrid: Alianza Editorial.

SILES, Jaime (1992): “Interiores". Alegoría. Madrid: Visor. (1999): Himnos tardíos. Madrid: Visor.

(2006): Estados de conciencia: ensayos sobre poesía Española contemporánea. Madrid: Abada editores.

(2014): "Las humanidades nos enseñan a no confundir precio y valor", 
ABC Cultural, 27 diciembre.

(2019): Arquitectura oblicua. Sevilla: Fundación José Manuel Lara.

(2019): Injertos y trasplantes. La traducción como proceso creativo. Edición de Rodrigo Olay Valdés. Valladolid: Ediciones Universidad de Valladolid.

VEYNE, Paul (2012): Mon musée imaginaire. Paris: Albin Michel. 